\title{
HERITABILITAS KECEPATAN LARI DAN TINGGI BADAN ANAK KUDA PACU UMUR 2 TAHUN DENGAN METODE KORELASI DALAM KELAS (INTRACLAS CORELATION)
}

\author{
Trisya T. Makalalag, Manopo J. H., H.F.N. Lapian dan U. Paputungan
}

Fakultas Peternakan Universitas Sam Ratulangi, Manado 95115

\section{ABSTRAK}

Penelitian ini bertujuan untuk mengetahui heritabilitas, kecepatan lari dan tinggi badan anak kuda pacu umur 2 tahun dengan Materi yang digunakan pada penelitian yaitu data perlombaan kuda pacu Indonesia berupa kecepatan lari dari beberapa perlombaan dengan berbagai jarak tempuh diperoleh dari koleksi data atau catatan kecepatan lomba kuda pacu di Indonesia (dari Steward pacuan kuda di Tompaso Feki Momuat). Catatan kecepatan lari hasil perlombaan pacuan dari kejuaraan nasional PORDASI selama sebelas tahun (1998 - 2012) dikumpulkan sebagai data yang diolah berdasarkan beberapa metode analisis untuk mendapatkan nilai heritabilitas untuk sifat ketahanan. Penelitian ini menggunakan metode Rancangan Korelasi Dalam Kelas (Intraclass Correlation) pada setiap individu yang mempunyai lebih dari dua data hasil pengukuran/penimbangan produksi. Berdasarkan hasil penelitian, pada anak keturunan Bunaken, betina lebih cepat dibandingkan dengan jantan, dan pada anak keturunan Sabeil Esa Tama, jantan lebih cepat dibanding betina, dan pada anak keturunan Century, Champ, Decibel, dan Manguni Makasiouw betina dan jantan sama cepat atau memiliki kecepatan yang sama antara jantan dan betina. Nilai heritabilitas kecepatan lari dan tinggi badan anak kuda pacu umur 2 tahun adalah tergolong sedang, yaitu masing-masing berkisar $0,15 \quad-0,29$ (kecepatan lari) dan 0,11 - 0,17 (tinggi badan). Tinggi badan anak kuda pacu dari enam pejantan memiliki korelasi positif yang sangat tinggi $(0,815-0,987)$, menunjukkan bahwa semakin tinggi ukuran badan akan semakin cepat pula tingkat kecepatan lari.

\section{Kata Kunci : Kuda pacu, kecepatan}

lari, tinggi badan, heritabilitas.

\section{ABSTRACT}

HERITABILITY OF SPEED AND BODY HEIGHT OF RACING HORSE AT TWO YEARS OLD USING INTRACLASS CORRELATION. This study was done to determine the heritability of speed and body height of running horse at two years old using intraclass correlation. Data used in the study were records of Indonesian racing 
horse in the form of running speed of several races with different mileage obtained from the collection of data records of race horse speed (from Steward race track in Tompaso FEKI Momuat). Note of speed run race results of the national championship race Pordasi for eleven years (1998 s / d 2012) were collected as data processed by several analytical methods to obtain the value of heritability for resistance properties. This study involved the design with intraclass correlation method used on each individual who has more than two data measurements/ weighing production. Based on the results of research and discussion, the Bunaken female offspring were faster than male offspring. The male offspring of Sabeil One Tama were faster than female offspring. The male and female offspring of Century, Champ, Decibel, and Manguni makasiouw females had the same speed. The heritability value of running speed and body height of race horse at two years old was moderate, ranging from 0.15 to 0.29 (running speed) and from 0.11 to 0.17 ( bodyheight). The height of six race horse had high positive correlation ( 0.815 to 0.987$)$, indicating that the higher the height of the body, the faster running speed of horse.

\section{Keywords: Racing horses, running} speed, body height, heritability.

\section{PENDAHULUAN}

Kuda sudah lama dikenal dan dimanfaatkan oleh manusia. Pemanfaatan kuda pada jaman dahulu hanya terbatas pada dagingnya saja, seiring berjalannya waktu, kuda mulai dimanfaatkan sebagai alat transportasi, dan kemudian berkembang menjadi hewan yang digunakan sebagai hobi dan sarana olahraga. Salah satu pemanfaatan kuda yang banyak ditemukan di Indonesia adalah sebagai kuda pacu. Kuda pacu Indonesia merupakan ternak lokal yang dapat beradaptasi dengan baik.

Kuda persilangan antara jantan Thoroughbred Australia dengan betina poni lokal, hasil turunanya disebut kuda Poni."Istilah kuda Poni ini bukan kuda pendek yang kecil tetapi hasil turunannya, baik turunan pertama, (G1,) kedua (G2), dan seterusnya memiliki postur badan yang besar. Persilangan ini menjadi syarat utama mengikuti pacuan kuda klasik yang diselenggarakan di Indonesia. Kuda pacu, salah satu jenis ternak yang perlu mendapat perhatian khusus karena merupakan sumber daya yang sangat strategis untuk dikembangkan (Oroh, 2004).

Potensi pengembangan peternakan kuda pacu di Sulawesi Utara sangat penting untuk ditingkatkan mengingat daerah ini merupakan salah satu daerah yang kaya bibit ternak kuda pacu 
unggul. Pengembangan ditujukan untuk kepentingan olahraga dan obyek wisata. Prospek peternakan kuda pacu di Kabupaten Minahasa khususnya Kecamatan Tompaso merupakan sentral pengembangan ternak kuda pacu, hal ini ditopang adanya fasilitas lapangan pacu yang berlokasi di wilayah Kecamatan Tompaso (Tulung, 2012).

Peningkatan produksi berbagai jenis dan bangsa ternak tidak hanya didukung oleh tatalaksana dan ketersediaan pakan yang baik, tetapi juga harus diikuti dengan bibit ternak yang bermutu genetik tinggi. Ketiga unsur pokok tersebut merupakan satu kesatuan yang tidak dapat dipisahkan dan saling menunjang satu sama lain.

Metode seleksi merupakan upaya pemuliaan untuk meningkatkan sifat ketahanan kuda pacu Indonesia, sehingga karakteristik kuda pacu Indonesia dapat dipertahankan. Nilai heritabilitas yang menggambarkan proporsi keunggulan suatu sifat dari ternak yang dapat diwariskan, terhadap sifat ketahanan kuda pacu Indonesia penting untuk diteliti sebagai upaya untuk menyeleksi pejantan yang unggul. Penelitian mengenai nilai heritabilitas kuda Indonesia masih sangat jarang dilakukan, untuk itu penelitian ini sangat penting dalam mendukung pengembangan potensi kuda pacu
Indonesia. Berdasarkan pemikiran tersebut maka telah dilaksanakan penelitian tentang heritabilitas kecepatan lari dan tinggi badan anak kuda pacu umur 2 tahun.

\section{MATERI DAN METODE PENELITIAN}

Materi terdiri dari 6 pejantan dan anak 276 ekor (anak pejantan 149 ekor dan anak betina 127 ekor). Data perlombaan kuda pacu Indonesia berupa data kecepatan lari dari beberapa perlombaan dengan berbagai jarak tempuh diperoleh dari koleksi data atau catatan kecepatan lomba kuda pacu di Indonesia (dari Steward pacuan kuda di Tompaso Feki Momuat). Catatan kecepatan lari hasil perlombaan pacuan dari kejuaraan nasional PORDASI selama 14 tahun (1998 -2012) dikumpulkan sebagai data yang diolah berdasarkan beberapa metode analisis untuk mendapatkan nilai heritabilitas untuk sifat ketahanan. Variabel yang diamati adalah Heritabilitas, Kecepatan Lari, Tinggi Badan, dan Korelasi.

Pendugaan nilai heritabilitas menggunakan Model rancangan percobaan berdasarkan Becker (1968) yaitu:

$$
Y_{i j}=\mu+\alpha_{i}+e_{i j}
$$

Keterangan :

$\mu=$ nilai tengah umum

$\alpha_{\mathrm{i}}=$ pengaruh pejantan ke-i

$\mathrm{e}_{\mathrm{ij}}=$ pengaruh lingkungan tak terkonrol dan atribut deviasi genetik individu dalam kelompok pejantan 
Nilai pendugaan heritabilitas dapat diperoleh dengan rumus Becker (1968) dengan metode One-way layout :

$\sigma_{w=}^{2} \mathrm{MS}_{\mathrm{w}}$ dan $\sigma_{s=\frac{\mathrm{MS} \mathrm{s}-\mathrm{MS}}{\mathrm{K}} \mathrm{w}}^{2}$

$$
h_{s}^{2}=\frac{4 \sigma_{\mathrm{s}}^{2}}{\sigma_{\mathrm{s}+\sigma_{\mathrm{w}}^{2}}^{2}}
$$

Ketangan:

$h_{s}^{2}=$ nilai heritabilitas dari pejantan

$\sigma_{w}^{2}=$ ragam antara individu dalam kelompok anak

$\sigma_{s}^{2}=$ ragam antar rata-rata kelompok anak dan pejantan

$\mathrm{MS}_{\mathrm{w}}=$ kuadrat tengah anak

$\mathrm{MS}_{\mathrm{s}}=$ kuadrat tengah pejantan

Dimana,

$$
k=\frac{1}{s-1}\left(\mathrm{n}-\frac{\sum \mathrm{n}_{\mathrm{i}}^{2}}{\mathrm{n}}\right)
$$

Keterangan:

$\mathrm{K}=$ koefisien dengan jumlah anak yang berbeda per pejantan

$n=$ jumlah anak total

$n_{\mathfrak{i}}=$ jumlah anak per pejantan

$\mathrm{s}=$ banyaknya pejantan

\section{HASIL DAN PEMBAHASAN}

Kecepatan lari kuda pacu Minahasa yang diamati pada penelitian ini disajikan pada Tabel 1. Berdasarkan Tabel 1 secara umum kecepatan lari kuda pacu Indonesia baik pada jantan maupun betina semakin meningkat seiring dengan penambahan umur. Hal ini sesuai dengan pernyataan Hintz (1980) bahwa pada kuda Thoroughbred di Amerika secara umum puncak performa pacu di capai pada umur empat tahun. Performa pacu seekor kuda dinilai dari kecepatan atau berapa cepat seekor kuda dapat berlari dan menyelesaikan pacuan.

Tabel 1 menunjukkan tingkat keragaman kecepatan lari kuda pacu ini memiliki variasi yang sangat tinggi berkisar 52,29 \% sampai 78,03\%. Kurnianto (2009) melaporkan bahwa koefisien keragaman yang melebihi $15 \%$ adalah termasuk kategori sangat tinggi.

Berdasarkan kecepatan lari kuda pacu jantan dan betina, yang memiliki nilai rataan kecepatan lari yang paling bagus atau yang paling cepat adalah Decibel dengan rataan 10,2621 m/detik. Pejantan Decibel memiliki nilai rataan yang paling tinggi diantara enam pejantan lainnya dan yang memiliki rataan kecepatan lari terendah adalah pejantan Champ dengan rataan 5,3980 $\mathrm{m} /$ detik. Sedangkan betina Bunaken memiliki kecepatan lari yang paling cepat dengan rataan 9,4217 m/detik. Betina Sabeil Esa Tama yang memiliki kecepatan lari terendah dengan rataan 5,1418 m/detik, Berdasarkan rataan keseluruhan, Decibel memiliki nilai rataan tertinggi yaitu 9,2053 m/detik, sedangkan yang memiliki nilai rataan terendah adalah Champ yaitu 6,2061.

Rekapitulasi hasil uji-t kecepatan lari kuda pacu jantan dan betina antara enam kelompok pejantan, yang diamati pada penelitian ini dapat dilihat pada Tabel 2. 
Tabel 1. Rataan kecepatan lari (m/detik) Anak kuda pacu jantan dan betina pada berbagai kelompok Pejantan.

\begin{tabular}{|c|c|c|c|}
\hline \multirow[t]{2}{*}{ Pejantan } & \multicolumn{2}{|c|}{ Jenis Kelamin Anak } & \multirow[b]{2}{*}{ Rataan Total $\hat{\delta} / Q$} \\
\hline & Rataan Jantan & Rataan Betina & \\
\hline Bunaken & $\begin{array}{l}6,1213 \pm 4,777 \\
(78,03 \%) \\
(n=17)\end{array}$ & $\begin{array}{l}9,4217 \pm 5,802 \\
(61,58 \%) \\
(n=16)\end{array}$ & $\begin{array}{l}7,7215 \pm 5,476 \\
(70,91 \%) \\
(n=33)\end{array}$ \\
\hline Century & $\begin{array}{l}8,7946 \pm 5,522 \\
(62,78 \%) \\
(n=20)\end{array}$ & $\begin{array}{l}8,7044 \pm 5,625 \\
(64,62 \%) \\
(n=29)\end{array}$ & $\begin{array}{l}8,7412 \pm 5,525 \\
(63,20 \%) \\
(n=49)\end{array}$ \\
\hline Champ & $\begin{array}{l}5,3980 \pm 3,783 \\
(70,08 \%) \\
(n=20)\end{array}$ & $\begin{array}{l}7,2837 \pm 5,260 \\
(72,21 \%) \\
(n=15)\end{array}$ & $\begin{array}{l}6,2061 \pm 4,503 \\
(72,55 \%) \\
(n=35)\end{array}$ \\
\hline Decible & $\begin{array}{l}10,2621 \pm 5,367 \\
(52,29 \%) \\
(n=28)\end{array}$ & $\begin{array}{l}8,1851 \pm 5,241 \\
(64,03 \%) \\
(n=29)\end{array}$ & $\begin{array}{l}9,2053 \pm 5,358 \\
(58,20 \%) \\
(n=57)\end{array}$ \\
\hline Manguni Makasiouw & $\begin{array}{l}6,8732 \pm 5,241 \\
(76,25 \%) \\
(n=36)\end{array}$ & $\begin{array}{l}7,3247 \pm 5,352 \\
(73,06 \%) \\
(n=15)\end{array}$ & $\begin{array}{l}7,0059 \pm 5,224 \\
(74,56 \%) \\
(n=51)\end{array}$ \\
\hline Sabeil E.Tama & $\begin{array}{l}8,6029 \pm 6,170 \\
(71,72 \%) \\
(n=28)\end{array}$ & $\begin{array}{l}5,1418 \pm 3,837 \\
(74,62 \%) \\
(n=23)\end{array}$ & $\begin{array}{l}7,0055 \pm 5,461 \\
(77,95 \%) \\
(n=51)\end{array}$ \\
\hline
\end{tabular}

Keterangan : angka persentase menunjukkan koefisien keragaman

Tabel 2.Rekapitulasi Hasil uji-t kecepatan lari kuda pacu antara jantan dan betina pada berbagai kelompok Pejantan

\begin{tabular}{|c|c|c|}
\hline Pejantan & Hasil uji-t & Nilai $\mathrm{P}$ \\
\hline Bunaken & $*$ & 0,042 \\
\hline Century & $\operatorname{tn}$ & 0,477 \\
\hline Champ & tn & 0,124 \\
\hline Decibel & tn & 0,072 \\
\hline Manguni Makasiouw & $\operatorname{tn}$ & 0,392 \\
\hline Sabeil E.Tama & $* *$ & 0,008 \\
\hline
\end{tabular}

Keterangan: $* *=$ Sangat nyata $*=$ Nyata $\mathrm{tn}=$ Tidak nyata

Berdasarkan Tabel 2, kecepatan lari kuda pacu yang sangat nyata, adalah pejantan Sabeil Esa Tama karena memiliki nilai $\mathrm{P}$ 0,008, sedangkan Bunaken memiliki uji-t nyata, dengan nilai P 0,042 dan hasil uji-t tidak nyata adalah pejantan Century, Champ, Decibel, Manguni Makasiouw, hanya memiliki nilai $P$ (0,477-0,124-0,072-0,392). 
Tabel 3. Rataan tinggi badan $(\mathrm{cm})$ Kuda Pacu Jantan dan Betina pada berbagai Kelompok Pejantan

\begin{tabular}{llll}
\hline Pejantan & \multicolumn{2}{c}{ Jenis Kelamin } & \\
& Rataan Jantan & Rataan Betina & Rataan Total $\delta /$ 促 \\
\hline Bunaken & $152,1176 \pm 3,426$ & $152,315 \pm 6,008$ & $152,2121 \pm 4,774$ \\
& $(2,25 \%)$ & $(3,94 \%)$ & $(3,13 \%)$ \\
& $(\mathrm{n}=17)$ & $(\mathrm{n}=16)$ & $(\mathrm{n}=33)$ \\
Century & $149,8050 \pm 4,134$ & $149,6759 \pm 4,442$ & $149,7285 \pm 4,345$ \\
& $(2,75 \%)$ & $(2,96 \%)$ & $(2,90 \%)$ \\
& $(\mathrm{n}=20)$ & $(\mathrm{n}=29)$ & $(\mathrm{n}=49)$ \\
Champ & $152,8500 \pm 2,978$ & $152,7667 \pm 5,473$ & $152,8142 \pm 4,158$ \\
& $(1,94 \%)$ & $(3,58 \%)$ & $(2,72 \%)$ \\
& $(\mathrm{n}=20)$ & $(\mathrm{n}=15)$ & $(\mathrm{n}=35)$ \\
Decible & $148,4071 \pm 4,124$ & $148,8414 \pm 4,296$ & $148,6280 \pm 4,180$ \\
& $(2,77 \%)$ & $(2,88 \%)$ & $(2,81 \%)$ \\
& $(\mathrm{n}=28)$ & $(\mathrm{n}=29)$ & $(\mathrm{n}=57)$ \\
Manguni Makasiouw & $147,6056 \pm 4,886$ & $146,5067 \pm 3,564$ & $147,2823 \pm 4,530$ \\
& $(3,31 \%)$ & $(2,43 \%)$ & $(3,07 \%)$ \\
& $(\mathrm{n}=36)$ & $(\mathrm{n}=15)$ & $(\mathrm{n}=51)$ \\
Sabeil E.Tama & $149,6429 \pm 3,972$ & $149,2292 \pm 4,450$ & $149,4519 \pm 4,162$ \\
& $(2,65 \%)$ & $(2,98 \%)$ & $(2,78 \%)$ \\
& $(\mathrm{n}=28)$ & $(\mathrm{n}=23)$ & $(\mathrm{n}=51)$ \\
\hline
\end{tabular}

Keterangan : Angka persentase menunjukan koefisien keragaman.

Data tinggi badan kuda pacu sesuai hasil penelitian dapat dilihat pada Tabel 3. Data tinggi badan pada Tabel 3 menunjukkan variasi yang rendah dengan koefisien keragaman hanya berkisar 1,94 $\%$ sampai 3,94 \%. Angka koefisien keragaman yang lebih rendah dari $5 \%$ dapat menunjukkan variasi yang sangat rendah (Kurnianto, 2009).

Nilai kecepatan lari kuda pacu jantan dan betina dapat dilihat pada Tabel 4.

Tabel 4.Nilai $\sigma_{w}^{2}$ dan $\sigma_{e}^{2}$ Kecepatan Lari Kuda Pacu Jantan dan Betina

\begin{tabular}{lccc}
\hline Sifat & Jenis Kelamin & $\sigma_{w}^{2}\left(\sigma_{g}^{2}+\sigma_{L T}^{2}\right)$ & $\sigma_{e}^{2}\left(\sigma_{L S}^{2}\right)$ \\
\hline Kecepatan Lari & $\sigma^{\top}$ & 2,179855 & 1,054149 \\
& $\propto$ & 28,0288 & 26,94265 \\
\hline
\end{tabular}

Keterangan $: \sigma_{w}^{2}=$ Kuadrat Tengah antara Individu, $\sigma_{e}^{2}=$ Kuadrat Tengah antara Pengamatan dalam Individu, $\sigma_{G}^{2}=$ Ragam Genetis, $\sigma_{L T}^{2}=$ Ragam Lingkungan Tetap, $\sigma_{L S}^{2}=$ Ragam Lingkungan Sementara 
Tabel 5.Nilai.$\sigma_{w}^{2}$ dan $\sigma_{e}^{2}$ Tinggi Pundak Kuda Pacu Jantan dan Betina

\begin{tabular}{lccc}
\hline Sifat & Jenis Kelamin & $\sigma_{w}^{2}\left(\sigma_{g}^{2}+\sigma_{L T}^{2}\right)$ & $\sigma_{e}^{2}\left(\sigma_{L S}^{2}\right)$ \\
\hline Tinggi Pundak & $\sigma^{\lambda}$ & 0,60045 & 1,075989 \\
& $\propto$ & 21,11001 & 23,7688 \\
\hline
\end{tabular}

Keterangan $: \sigma_{w}^{2}=$ Kuadrat Tengah antara Individu, $\sigma_{e}^{2}=$ Kuadrat Tengah antara Pengamatan dalam Individu, $\sigma_{G}^{2}=$ Ragam Genetis, $\sigma_{L T}^{2}=$ Ragam Lingkungan Tetap, $\sigma_{L S}^{2}=$ Ragam Lingkungan Sementara

Tabel 4 menunjukkan bahwa sifat kecepatan lari antara jantan dan betina memiliki nilai yang berbeda atau memiliki nilai kecepatan lari yang berbeda, karena betina memiliki nilai yang lebih tinggi sedangkan jantan memiliki nilai yang lebih rendah.

Tinggi pundak atau tinggi badan kuda pacu jantan dan betina dapat dilihat pada Tabel 5. Data Tabel 5 menunjukkan bahwa sifat tinggi pundak atau yang memiliki tinggi pundak yang paling bagus adalah betina karena pada perhitungan tabel di atas betina yang memiliki nilai pundak yang paling tinggi dibanding jantan.

Heritabilitas $\left(\mathrm{h}^{2}\right)$ berhubungan dengan proporsi keragaman genotipik yang dikontrol oleh gen. Proporsi ini dapat diwariskan pada generasi selanjutnya, dengan nilai berkisar antara 0-1 (Noor, 2008), nilai heritabilitas dapat dikelompokkan kedalam tiga kelompok sebagai berikut: (1) heritabilitas rendah yaitu <0,0 (0-10\%), (2) heritabilitas sedang yaitu berkisar antara 0,1-0,3, heritabilitas tinggi yaitu lebih besar dari 0,3 (30\%) (Martojo, 1992). Pada dasarnya perhitungan heritabilitas didasarkan pada prinsip bahwa ternak-ternak yang memiliki hubungan keluarga akan memiliki performa yang lebih mirip jika dibandingkan dengan ternak-ternak yang tidak memiliki hubungan keluarga. Perhitungan heritabilitas nyata memerlukan perbandingan antara performa tetuanya, dalam hal ini sebenarnya kita membandingkan rataan keunggulan anak dengan keunggulan tetuanya (Noor, 2008).

Metode pendugaan nilai $\left(\mathrm{h}^{2}\right)$ perlu disesuaikan dengan rancangan percobaan yang digunakan (Warwick et al, 1987). Menurut Noor (2008), perhitungan heritabilitas dapat dilakukan dengan metode regresi. Pada perhitungan dengan metode regresi diasumsikan bahwa jika keragaman antara dua populasi tidak berbeda, maka regresi anak dengan rataan tetuanya dapat digunakan untuk mengestimasi nilai heritabilitas suatu sifat.

Anak hanya mewarisi setengah gen-gen dari salah satu tetuanya, sehingga 
heritabilitas dapat juga diestimasi dari regresi antara anak dengan salah satu tetuanya. Heritabilitas yang diestimasi dengan cara ini adalah sebesar $2 \mathrm{x}$ koefisien regresinya. Ternak-ternak yang memiliki hubungan keluarga fullsib (saudara kandung) memiliki kesamaan gen sebesar
$50 \%$. Oleh sebab itu, nilai heritabilitasnya adalah sebesar $2 \mathrm{x}$ koefisien regresinya. Ternak-ternak yang memiliki hubungan keluarga halfsib (saudara tiri) memiliki kesamaan gen sebesar $25 \%$ jadi, estimasi heritabilitasnya adalah $4 \mathrm{x}$ koefisien regresi.

Tabel 6. Nilai Heritabilitas Kecepatan Lari dan Tinggi Pundak Kuda Pacu Jantan dan Betina

\begin{tabular}{lcl}
\hline Sifat & Jenis Kelamin & Nilai Heritabilitas \\
\hline Kecepatan Lari & 0 & 0,28864 \\
& 0 & 0,15061 \\
\hline
\end{tabular}

Sifat

Jenis Kelamin

Nilai Heritabilitas

Tinggi Pundak

0,110629

0,173234

Pada Tabel 6 Nilai Heritabilitas Kuda Pacu Jantan dan Betina, menyatakan bahwa sifat kecepatan lari antara jantan dan betina memiliki nilai heritabilitas sedang $(0,15-0,29)$, dan pada sifat tinggi pundak, jantan dan betina juga memiliki nilai heritabilitas sedang $(0,11-$ $0,17)$

Tabel 7. Korelasi antara Kecepatan Lari dan Tinggi Pundak Kuda Pacu Minahasa Jantan dan Betina pada berbagai Kelompok Pejantan yang Berbeda

\begin{tabular}{|c|c|c|c|c|c|c|}
\hline \multirow{2}{*}{$\begin{array}{c}\text { Kelompok Pejantan } \\
(\mathrm{P}<0,01)\end{array}$} & \multirow{2}{*}{$\begin{array}{c}\text { Jumlah } \\
\text { Anak (n) }\end{array}$} & \multirow{2}{*}{$\begin{array}{c}\text { Jenis } \\
\text { Kelamin }\end{array}$} & \multirow{2}{*}{$\begin{array}{c}\text { Nilai } \\
\text { Korelasi }\end{array}$} & \multirow[t]{2}{*}{ thitung } & \multicolumn{2}{|c|}{$\mathrm{t}$ tabel } \\
\hline & & & & & 0,05 & 0,01 \\
\hline \multirow[t]{2}{*}{ Bunaken } & 17 & $\overline{0}$ & 0,987 & $23,670 * *$ & 2,131 & 2,947 \\
\hline & 16 & o & 0,848 & $5,7823 * *$ & 2,145 & 2,977 \\
\hline \multirow[t]{2}{*}{ Century } & 20 & $0^{\lambda}$ & 0,815 & $5,9734 * *$ & 2,101 & 2,878 \\
\hline & 29 & 우 & 0,925 & $12,660 * *$ & 2,056 & 2,779 \\
\hline \multirow[t]{2}{*}{ Champ } & 20 & $0^{\lambda}$ & 0,967 & $16,175^{* *}$ & 2,101 & 2,878 \\
\hline & 15 & q & 0,946 & $10,577^{* *}$ & 2,160 & 3,012 \\
\hline \multirow[t]{2}{*}{ Decibel } & 28 & $0^{\lambda}$ & 0,901 & $10,616^{* *}$ & 2,056 & 2,779 \\
\hline & 29 & q & 0,903 & $10,927^{* *}$ & 2,052 & 2,771 \\
\hline Manguni & 36 & $0^{\lambda}$ & 0,823 & $8,4522 * *$ & 2,042 & 2,750 \\
\hline Makasiow & 15 & q & 0,925 & $8,7823^{* *}$ & 2,160 & 3,012 \\
\hline \multirow[t]{2}{*}{ Sabeil Esa Tama } & 28 & $\sigma^{\lambda}$ & 0,942 & $14,409 * *$ & 2,056 & 2,779 \\
\hline & 23 & 우 & 0,867 & $8,1752 * *$ & 2,080 & 2,831 \\
\hline
\end{tabular}

Ket: **Sangat Nyata $(\mathrm{P}<0,01)$ 
Jika koefisien keragaman pada dua populasi yang diamati tidak berbeda jauh, maka koefisien korelasi dapat digunakan untuk menghitung heritabilitas.

\section{Nilai Heritabilitas Kuda Pacu} Jantan dan Betina dapat dilihat pada Tabel 6. Data Tabel 6 menunjukkan bahwa sifat kecepatan lari antara jantan dan betina memiliki nilai heritabilitas sedang $(0,15-$ 0,29), dan pada sifat tinggi pundak, jantan dan betina juga memiliki nilai heritabilitas sedang $(0,11-0,17)$.

Koefisien korelasi antara tinggi pundak dan kecepatan lari kuda pacu Minahasa jantan dan betina pada berbagai kelompok pejantan yang berbeda. Hasilnya sangat nyata $(\mathrm{p}<0,01)$, dan bernilai pasitif. Hal ini menunjukkan bahwa antara tinggi pundak dan kecepatan lari kuda pacu Minahasa jantan dan betina pada berbagai kelompok yang berbeda memiliki nilai korelasi yang berbeda. Ini berarti bahwa semakin tinggi pundak anak kuda pacu semakin cepat pula tingkat kecepatan lari kuda pacu.

\section{Falconer (1972) menyatakan} bahwa bila korelasi genetik bernilai positif, maka peningkatan salah satu sifat akan mengakibatkan sifat yang lebih meningkat pula. Namun bila yang terjadi kebalikannya maka dapat pula bernilai negatif.

Warwick et al. (1987) menyatakan bahwa suatu dugaan korelasi genetik harus dianggap hanya dapat diterapkan pada populasi tertentu dan pada waktu tertentu pula. Kenyataan bahwa korelasi genetik dapat benar-benar berubah dalam populasi yang sama selama beberapa generasi apabila terdapat selisih, yang intensif untuk satu alam beberapa sifat. Kemungkinan, sebab perubahan ini adalah bahwa dengan adanya seleksi maka frekuensi gen-gen dengan pengaruh pleiotropik positif meningkat atau tetap, akibatnya hanya gen-gen dengan pengaruh pleiotropik negatif yang mengalami segragasi.

Falconer (1972) menyatakan bahwa kejadian pleiotropik adalah bila satu gen dapat mempengaruhi dua atau lebih sifat yang lain. Misalnya gen yang mempengaruhi tinggi pundak, mempengaruhi bobot badan dan kenaikan pertumbuhan.

Korelasi antara kecepatan lari dan tinggi pundak kuda pacu Minahasa jantan dan betina pada berbagai kelompok pejantan yang berbeda dapat dilihat pada Tabel 7. Data Tabel 7 menunjukkan bahwa pada enam (6) kelompok pejantan yang berbeda memiliki nilai korelasi yang berbeda dan pada enam (6) kelompok pejantan yang berbeda tersebut dengan tingkat kecepatan yang sangat tinggi ( $P$ $<0,01)$. Hal ini menunjukkan bahwa semakin tinggi pundak anak kuda pacu, 
semakin cepat pula tingkat kecepatan lari kuda pacu.

\section{KESIMPULAN}

Berdasarkan hasil penelitian dapat disimpulkan pada keturunan Bunaken, betina lebih cepat dibandingkan dengan jantan, dan pada anak keturunan Sabeil Esa Tama, jantan lebih cepat dibanding betina, dan pada keturunan Century, Champ, Decibel, dan Manguni Makasiouw betina dan jantan sama cepat / memiliki kecepatan yang sama antara jantan dan betina.

Nilai heritabilitas kecepatan lari dan tinggi badan anak kuda pacu umur 2 tahun adalah tergolong rendah sampai sedang, yaitu masing-masing berkisar 0,15 - 0,29 (kecepatan lari) dan 0,11 - 0,17 (tinggi badan).

Tinggi badan anak kuda pacu dari enam pejantan memiliki korelasi positif yang sangat tinggi $(0,815-0,987)$ yang menunjukkan bahwa semakin tinggi ukuran badan akan semakin cepat pula tingkat kecepatan lari.

\section{DAFTAR PUSTAKA}

Becker, W. A. 1968. Manual of procedures in Quantitative Genetics. $2^{\text {nd }}$ ED.

Washington State University Press, Washington.
Falconer, D.S. 1972. Introduction to Quantitative Genetics The Ronald Press Company. New York.

Hintz, R. L. 1980. Genetic of Performance in the Horse. J. Anim. Sci. 51:582-594

Kurnianto, E. 2009. Pemuliaan Ternak. Catatan Pertama, Penerbit Graha Ilmu, Yogyakarta.

Martojo, H. 1992. Peningkatan Mutu Genetik Ternak. Departemen Pendidikan dan Kebudayaan. Direktorat Jendral Pendidikan Tinggi. Pusat Antar Universitas Bioteknologi, IPB, Bogor.

Noor, R. R. 2008. Genetika Ternak. Cetakan ke-4. Penebar Swadaya, Jakarta.

Oroh, R. K. P. 2004. Determinasi Kebutuhan Energi Untuk Kerja Berdasarkan Jumlah Pakan yang dikonsumsi Dalam Bahan Kering, Bobot Metabolik, Dan Beban Kerja Kuda Pacu. Skipsi. Fakultas Peternakan - Unsrat, Manado.

Tulung Y. L. R. 2012. Kebutuhan Energi dan Nutrien Kuda Pacu Indonesia dan Aplikasi Pada Formulasi Ransusm Berbasis Pakan Lokal. Disertasi. Pascasarjana Institut Pertania Bogor.

Warwick, E. J., J. Maria Astuti dan W. Harjosubroto. 1987. Pemuliaan Ternak. Gadjah Mada University Press, Yogyakarta.

Wiliams, C.A., D. S. Kronfeld, T. M. Hess, K.E. Saker, J. N. Waldron, K. M. Crandell, R. M. Hoffman, \& P. A. Harris. 2004. Anioxidant Suplement And subsequent oxidative stress of horses during an 80-km endurance Race. J. Anim. Sci. 82:588-594. 